\title{
Logotipo ou quadrinho? As animadas aventuras de Don Quixote nas capas de Ângelo Agostini
}

\section{Lopes Pinheiro Queluz, Marilda}

Resumen:

El objetivo de este texto es reflexionar sobre las portadas del diario Don Quijote, fundado en 1895, por el inmigrante italiano Ângelo Agostini (1843-1910), enfatizando los recursos metalingüísticos creados en torno a la idea de construcción del logotipo y el establecimiento de una narrativa secuenciada para la identidad visual del periódico. El contexto de decepción con el inicio del régimen republicano oligárquico brasileño y de desconfianza con la modernización tecnológica dialoga con las confusiones y divertidas aventuras de los personajes cervantinos en los animados encabezados de Agostini. El eximio trazo académico del caricaturista experimenta, en la litografía, nuevos rumbos para el

Cuadernos del Centro de Estudios de Diseño y Comunicación №74

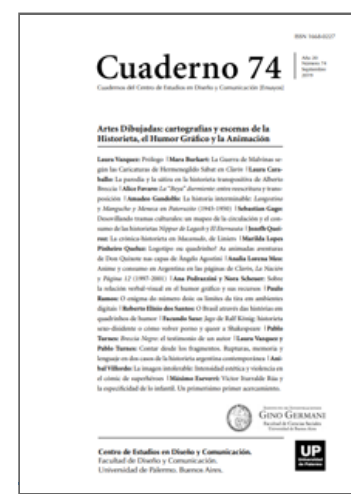

ISSN: 1668-0227

Artes Dibujadas:

cartografías y

escenas de la

Historieta, el Humor

Gráfico y la

Animación

Año XX, Septiembre 2019, Buenos

Aires, Argentina | 256 páginas

descargar PDF

ver índice de la publicación

Ver todos los libros de la publicación

compartir en Facebook lenguaje del humor gráfico, dejando entrever, aunque por un sesgo conservador, las transformaciones de la ciudad y de la prensa.

Palabras clave: Don Quijote - Agostini - historieta - humor gráfico.

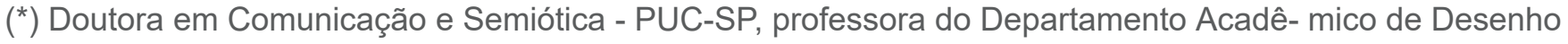
Industrial e do Programa de Pós-Gradualçao em Tecnologia (PPGTE) da Universidade Tecnológica Federal do Paraná - UTFPR.

Ângelo Agostini (1843-1910)1 foi, sem dúvida, um dos nomes mais expressivos da caricatura e das artes gráficas do século XIX no Brasil. A crítica mordaz e a precisão de seu lápis aprimoraram as possibilidades da litografia e a qualidade das revistas ilustradas. Entre suas inúmeras façanhas, está o fato de ser reconhecido como um dos pioneiros dos quadrinhos brasileiros. Coube-lhe: 
A glória de ter sido um dos precursores, no mundo, das histórias em quadrinhos, e de ter publicado, no longínquo ano de 1869, a primeira novela- -folhetim em quadrinhos de que se tem notícia, As Aventuras de NhôQuim, ou Impressões de uma viagem à Corte, continuadas depois em As Aventuras de Zé Caipora, quando Agostini já era dono de técnica narrativa impressionante, que se traduzia em sequências verdadeiramente cinematográficas. (Cagnin, 2005, p. 18)

Mas, o que nos interessa discutir neste texto é a atuação de Agostini nas capas de Don Quixote2 , considerando as sequências narrativas criadas em torno do cabeçalho e do logotipo do periódico, animadas por uma versão tupiniquim dos personagens cervantinos. Além do cavaleiro da triste figura parecer uma espécie de alter ego de Agostini, é intrigante pensar como esta representação daria conta de traduzir as relações entre o repórter visual -artista e intelectual-, os leitores e o cotidiano político.

Mesmo se tratando de imagens do passado, aquelas que já adquiriram um caráter de preciosas fontes históricas, como estas charges oitocentistas, é fundamental ressaltar a polissemia e a ambiguidade:

As imagens não são nem um reflexo da realidade social nem um sistema de signos sem relação com a realidade social, mas ocupam uma variedade de posi- ções entre estes extremos. Elas são testemunhas dos estereótipos, mas também das mudanças graduais, pelas quais indivíduos ou grupos vêem o mundo social, incluindo o mundo de sua imaginação. (Burke, 2004, p. 232)

Quando Don Quixote foi lançado, em 18953 , o desenhista já havia sido consagrado por seus combates abolicionistas e seus ataques à monarquia de D. Pedro II. A queda do Império não trouxe mudanças na estrutura econômica latifundiária e muito menos nas relações de trabalho, excluindo a população negra e os brasileiros e imigrantes pobres dos direitos de cidadania. O Brasil experimentava o desencanto com o novo regime político4 e a decepção com as promessas de modernizar e civilizar o país e sua capital, o Rio de Janeiro. Era o início da República oligárquica, do governo civil de Prudente de Morais (1894-1898).

O arranjo político que melhor expressava o projeto do abolicionismo racista -com a consequente importação de força de trabalho europeia- era a República Oligárquica. Excludente, elitista, antidemocrático e mantenedor da grande propriedade da terra, esse era o regime dos sonhos de um setor majoritário das classes dominantes que aceitou a libertação como parte de um projeto de modernização conservador. (Maringoni, 2011, p. 205)

Agostini apoiou esse projeto e, por isso, seus traços e suas críticas apresentam as contradi- ções e as angústias com o final do século, a descrença na política e no futuro do país. Talvez aí esteja o motivo da escolha de Don Quixote para representar seus ataques à imprensa e ao governo, atualizando o personagem seiscentista espanhol de Miguel de Cervantes 5 para os trópicos brasileiros, bem como o fiel escudeiro Sancho Pança, o cavalo Roncinante e o burro. Esse título era muito comum em jornais da época e já fora utilizado em outros periódicos ilustrados de diversos países da América Latina.

Na América hispânica, em meados do século XIX e início do XX, várias obras reconstroem parodicamente as figuras de D. Quixote e Sancho como motivo de sátira político-social à nacionalidade. Predomina a ideia de que por trás do riso e da caricatura está a reflexão filosófica, resultando daí o caráter universal da obra. (Velloso, 1996, p. 140) 
O personagem recriado por Agostini e que daria nome a sua folha de notícias era lúcido e perspicaz, descontente com a política fraca de Prudente de Morais, representado, muitas vezes, de olhos fechados ou como uma marionete, denominado pelo caricaturista como Prudente De Mais (Ipanema, 2013).

Tanto para Joaquim de Andrade (2004), como para Gilberto Maringoni (2011), Don Quixote foi uma das últimas publicações em litografia com uma certa expressividade a circular no Rio de Janeiro. O periódico surgiu em um momento em que os processos de reprodução fotomecânicas começavam a se disseminar, com uma maior qualidade de impressão, exibindo cores, combinando fotografia e ilustração em uma diagramação mais arrojada graças à zincografia, em tiragens maiores e a preços mais acessíveis para o crescente público urbano.

A folha de Agostini trazia ilustrações extremamente detalhadas, explorando todo o espa- ço das páginas centrais, com "cenas abertas de tragédias, desfiles carnavalescos, batalhas campais, situações épicas, ou mesmo simples retratos de personalidades que admirava." (Maringoni, 2011, p. 167)

Na capa da primeira edição (Ver Figura 1), os personagens se apresentam. Don Quixote, em primeiro plano, montado em seu cavalo, carrega uma lança que funciona como estandarte, uma bandeira que tremula ao vento, com o nome do jornal ilustrado. A ponta da lança cruza a fronteira da moldura, para além da cena e dos limites gráficos. Sancho Pança, em seu burro, caminha em nossa direção, no instante em que vai tirar o chapéu para nos saudar. Os moinhos ao fundo reiteram a referência e a identidade dos personagens.

A inspiração de Agostini vem das xilogravuras de Gustave Doré (1833-1883), cujas ilustra- ções da obra de Cervantes "tornaram-se, com o tempo, a mais difundida tradução visual do cavaleiro da triste figura". (Maringoni, 2011, p. 171)

No editorial da primeira edição de Don Quixote, afirma-se a afinidade com o "desgastado e engenhoso fidalgo de La Mancha" e a necessidade de se lutar contra os "prejuízos morais" e contra os "abusos" do poder em defesa dos fracos "que são, na maioria dos casos, os que não têm consciência de sua força." (Don Quixote, 1895, p. 2). A ironia e a ambiguidade parecem convergir para uma pátria que soa como mentira e ilusão, como Dulcinea:

Pois bem: com o pensamento na sua Dulcinea, que é esta pátria brasileira, tão bela e tão forte, o Don Quixote, que ora se apresenta, está resolvido e pronto a quebrar muitas lanças pelo seu grande ideal, que é: Mais civilização, mais progresso, mais humanidade. (Don Quixote, 1895)

Nas páginas centrais deste mesmo número (Ver Figura 2), há uma citação visual do personagem ilustrado por Gustave Doré e uma comparação com o Don Quixote brasileiro. Enquanto a legenda do desenho espanhol, à esquerda, explica "Encheu-se-Ihe a fantasia de tudo que se achava nos livros", o personagem de Agostini, à direita, é assombrado "pela fantasia de tudo que se acha nos jornais". Ali vê-se a jovem Imprensa Independente amordaçada e com as mãos amarradas, e os vários conflitos que agitavam as províncias brasileiras.

A intertextualidade com a obra de Cervantes e os paralelos com as aventuras quixotescas são constituídos pela paródia da situação do país e da atuação da imprensa brasileira.

Monica Velloso, ao estudar as influências hispânicas literárias no modernismo do final do século XIX e início do século XX, questiona: "qual o poder de síntese contido na dupla D. Quixote/Sancho? Como esses personagens 
saem das páginas de um clássico do século XVII para se integrarem ao moderno contexto brasileiro?" (Velloso, 1996, p. 130)

A historiadora demonstra que havia um sentimento comum, entre os intelectuais espanhóis oitocentistas e os nossos modernistas, de rechaçar a política "como espécie de corpo estranho à modernidade. Deposita-se, de modo geral, uma confiança ingênua no poder da arte e da literatura como instrumento de transformação social". (Velloso, 1996, p. 135) Assim como Don Quixote, Agostini se coloca como um personagem deslocado do mundo a sua volta, queixando-se da raridade de assuntos interessantes para os jornais, deixando entrever uma falta de engajamento e uma visão moralista. Tratava a política como "algo distanciado do jornal e não como o embate de ideias, interesses e forças na sociedade, na qual todos os seus membros, direta ou indiretamente, estão envolvidos". (Maringoni, 2011, p. 168)

Ao final do século XIX os olhares de desencanto voltam-se para a vida cotidiana, acreditando que a sociedade precisaria passar por um processo de regeneração, pautado em novos parâmetros baseados na ciência e na razão, por um viés conservador. Imaginar um futuro melhor para as cidades passa a fazer parte da agenda de artistas e intelectuais. Colocar-se fora da realidade seria o melhor jeito de compreendê-la, usando estratégias como o humor, o absurdo, a exposição ao ridículo. A opção por reler o cavaleiro da triste figura se daria pela afinidade com seu projeto derrotado, impossível. O que se busca na obra de Cervantes é a sensação de que só o nonsense e o riso podem avançar contra o mundo das aparências. Logo, só um Don Quixote conseguiria enxergar a humanidade em sua essência, só um herói enlouquecido conseguiria revelar a verdade. (Velloso, 1996, p. 139)

A obra de Cervantes acolhe a justaposição de elementos culturais distintos, fato que também caracteriza a história da América Latina. Daí por que seus personagens têm atualidade e impacto simbólicos entre nós. Por outro lado, servem de metáfora e emblema para expressar uma realidade marcada pela contradição, pela ambiguidade e por contrastes socioculturais profundos. A própria oscilação cervantina entre ficção, realidade, mentira e verdade e a intercomunicação incessante entre esses domínios nos são extremamente familiares. (...) É nítido o desencanto latino com o universo da política republicana vivenciado enquanto farsa, mentira e ficção. (Velloso, 1996, p. 144)

A metalinguagem e a autorreferência são recursos recorrentes utilizados por Agostini e são fundamentais na experimentação da linguagem do humor gráfico. Um exemplo interessante é o diálogo visual entre o próprio autor, desenhando na pedra litográfica, e os personagens Don Quixote e Sancho Pança. (Ver Figura 3)

Nesse sentido, Agostini se apropria do procedimento muito usado na obra cervantina:

Deslocando o tradicional eixo narrador-narrativa-leitor, a obra estabelece múltiplas possibilidades de interpretação. Assim, volta e meia o autor -Cervantes ou D. Quixote- interfere no texto, expressando sua opinião sobre o mesmo. Também o leitor é convidado, direta ou implicitamente, a opinar e participar da construção narrativa (...) busca-se estabelecer uma cumplicidade entre o leitor e o narrador, em que o primeiro se sente interatuando no desenvolvimento do enredo. (Velloso, 1996, p. 143)

As notícias da semana e o cotidiano do Rio de Janeiro eram interpretados pelos desenhos de Agostini em narrativas sequenciadas, marcadas por grande dinamismo gráfico, criando verdadeiras crônicas visuais. Essa 
estratégia estava presente na maior parte de seus trabalhos, embora tenham alcançado seu auge em, pelo menos, dois momentos: nos quadrinhos (As aventuras de Nhô Quim, As aventuras de Zé Caipora) e nas capas de Don Quixote.

"Repórter do lápis, como gostava de chamar-se, não se satisfazia com uma única imagem dos personagens e fatos. Suas caricaturas desdobravam-se em inúmeras outras, em sequ- ência, como se tentasse dar-lhes movimento e vida". (Cagnin, 2005, p. 18)

A narrativa em torno da construção do logotipo, trazendo uma nova cena a cada número do periódico, constrói uma aventura paralela, sem palavras, em uma sequência que lembra muito os primeiros desenhos animados. Na segunda edição, Sancho Pança aparece pintando a placa com o título do jornal, uma simples atividade que transforma o cabeçalho em palco de muitas trapalhadas e confusões (Ver Figuras 4 e 5).

Nesta narrativa da construção do cabeçalho e da elaboração do título do periódico, na sequência da pintura das letras, traçadas manualmente, e do preenchimento com tinta, destaca-se o valor do trabalho, do tempo do serviço -lento, gradual-, a dedicação de Sancho Pança e seu esforço a cada número da revista, como metáfora do próprio fazer da litografia. Diante das trapalhadas do burro, esfregando-se e borrando o letreiro, culminando com os coices dele e de Roncinante na placa, para desespero de Sancho, resta o improviso do tecido amarrado a duas varas (Ver Figura 6).

Ao comentar essa brincadeira com o título do jornal e o modo como os leitores eram convidados a participar deste jogo, Maringoni faz uma comparação com Will Eisner:

O surpreendente dessa sequência gráfica é a narrativa montada, perceptível somente por um leitor constante, que colecionasse todas as edições. Ela só faz sentido em seu conjunto. O apuro formal aqui registrado só teria equivalente nas histórias em quadrinhos norte americanas na década de 1940, quando Will Eisner (1917-2005), criador do personagem The Spirit, trabalharia os logotipos de suas histórias com abordagem semelhante. É necessário ressaltar a palavra semelhante, pois enquanto Agostini fazia do símbolo de seu jornal um personagem de uma narrativa, Eisner, meio século depois, limitava-se a criar uma marca a cada semana, sem maiores arroubos narrativos. (Maringoni, 2011, p. 171)

A segunda tentativa (Ver Figura 7) de construir o cabeçalho sugere um projeto mais elaborado, observado na precisão da letra técnica, com uma tipografia mais profissional, com cuidado na diagramação, no alinhamento e no espaço entre as linhas.

Na capa da Figura 8, vemos a tinta escorrendo, como estratégia de metalinguagem, interrompendo a ação intelectual de Don Quixote (ou de Agostini?), provocando o deslocamento de um quadro para o outro (Ver Figura 9), borrando os limites entre os espaços das cenas retratadas pelo jornal e o espaço da identidade visual do periódico, subvertendo a diagramação da página. Trama-se na composição uma metáfora do espaço fictício misturando-se ao suposto espaço público, transitando entre a seriedade e a comicidade, a fantasia e a realidade, a imprensa e o que acontecia nas ruas e no governo.

A reação do personagem, de abandonar seu posto e perseguir seu fiel escudeiro provoca uma sequência hilária, nonsense, digna de uma cena de filme de pastelão (Ver Figura 10). Na sequência, há a destruição da tabuleta 
com o nome do jornal por quatro índios (Ver Figura 11), agindo com fúria e de modo insensato. A presença de índios neste cabeçalho é uma incógnita, pois eles sempre apareceram na obra de Agostini como símbolos do Brasil, ainda que em uma visão romântica e eurocêntrica, como heróis que representavam a pátria e a nacionalidade. Entretanto, aqui aparecem associados à selvageria, à violência, impedindo o estabelecimento do logotipo, a consolidação do jornal. Em outro momento, Sancho e o fidalgo são caracterizados com trajes indígenas, destacando os tempos selvagens que o país atravessava (Ver Figura 12). Essa mudança de significados e valores atribu- ídos a esse grupo reforça o preconceito e o conservadorismo, reiterando a imagem de que este país não era civilizado e estava longe do modelo ideal de progresso branco e europeu. O desfecho desta narrativa é o apelo a mais um improviso, colocando-se novamente um lençol, uma grande faixa de tecido pendurada por pregos, com o título do periódico. Um detalhe que acompanharia todos os cabeçalhos é o aviso entre parêntesis de que este é um frontispício provisório (Ver Figura 13).

Na edição número 45, inicia-se outra saga para a instalação de um logotipo definitivo (Ver Figura 14). Observase o esforço para levantar uma carga pesada, com o auxílio de cordas, gancho e roldana, demandando grande empenho dos quatro personagens. Há uma sofisticação de equipamentos para a composição do título. A preocupação com o aperfeiçoamento técnico pode ser vista no desenho da "encomenda frágil", vinda do Rio de Janeiro, em um grande caixote de madeira. Parecem tipos ou o logotipo pronto. Mas, um acidente interrompe os trabalhos, destrói a caixa e estraga seu conteúdo, partindo o logotipo em vários pedaços.

A situação se agrava com uma inundação (Ver Figura 15), decorrente das chuvas intermitentes e dos alagamentos noticiados nos jornais, deixando nossos bravos heróis sem muitas opções. Interessante como os eventos trágicos do Rio de Janeiro passam a fazer parte do cenário da revista, protelando/inviabilizando a reestruturação do cabeçalho. Problemas das enchentes, da cidade, tornam-se problemas da revista. Propõe-se uma paródia das tragédias urbanas, ironizando as dificuldades de infraestrutura e a falta de recursos técnicos. A cena de equilíbrio, pós dilúvio, pode ser uma metáfora visual da revista tentando sobreviver, mesmo em momentos conturbados, mesmo consciente da litografia estar na iminência de tornar-se uma técnica obsoleta, concorrendo com outros produtos grá- ficos. Sancho pendurado, sendo ajudado na capa seguinte por Don Quixote, faz pensar em um gesto de resistência, uma incrível façanha de Agostini para se manter no mercado. Decide-se, então, por uma faixa improvisada, desta vez, fixada com pregos. Chama a aten- ção uma capa em que vemos no cabeçalho a cena de Sancho Pança remendando a faixa (Ver Figura 16). Pode-se refletir sobre a escolha do fiel escudeiro, com os pés plantados na realidade, a vista dos leitores, para representar o papel do artista gráfico, designer, diretor de arte, editor, unindo trabalho intelectual e artesanal, dando ênfase na própria fatura da capa, no investimento visual e na materialidade do jornal. Agostini parece insistir no processo litográfico como uma batalha solitária em busca da perfeição entre arte e técnica - techné, no sentido grego de fabricação, habilidade e criatividade.

O cabeçalho do jornal remete a uma cortina, um lençol ou um pano de cena, atrás do qual os personagens se escondem. Funciona como um refúgio, um posto de observação, um local secreto em cumplicidade com o leitor, de onde é possível interagir com o mundo político e o cotidiano. Até 1897, torna-se um espaço privilegiado (Ver Figura 17): às vezes é enfeitado com adornos para comemorações cívicas; às vezes é transformado pelas decisões políticas. O cabeçalho passa a assumir múltiplas funções, evidenciando a capa como suporte e como processo midiático. 
As capas de Don Quixote, além de interpretarem o contexto nacional e opinarem sobre a política da época, propõem uma discussão visual sobre tecnologia e invenção criativa. Experimenta-se a inovação da linguagem gráfica, mesmo em uma técnica que já começava a ficar ultrapassada. Parte-se da imaginação, das aventuras tumultuadas dos personagens inspirados em Cervantes para os quadrinhos sem palavras, simulando quase uma animação. Don Quixote era um jornal caro, voltado para uma pequena parcela da sociedade, recheado de comentários elitistas, conservadores e até mesmo racistas. Trazia muitas críticas às transformações urbanas, reclamando das aglomerações, dos acidentes, do péssimo estado de conservação das ruas. A visão da cidade que se construía a cada número era a de um inferno, onde o perigo, a sujeira e a violência eram constantes. Alimentava-se o sentimento das classes dominantes de desencanto com a república e com o país.

Para Maringoni, Agostini, assim como Don Quixote, era um personagem anacrônico:

Agostini pertencia a outra época, às décadas que antecederam o fim do Impé- rio. Como artista, ele assistiria ao surgimento de profissionais que não bebiam mais de sua fonte estética, mas buscavam influência numa geração que florescia na França e na Alemanha. Estes repeliam o academicismo na caricatura e aproximavam-se tanto do art nouveau, quanto do expressionismo. A analogia de Agostini com o fidalgo cervantino não se dá pelo combate a moinhos de vento, mas pelo passadismo que ambos encarnaram a certa altura da vida. (Maringoni, 2011, pp. 208-209)

Apesar de Agostini estar trabalhando com uma técnica antiquada, que não seria deixada de lado, mas teria outros rumos artísticos, experimenta novos usos da linguagem litográfica, para além dos quadrinhos, inventando novas propostas de identidade visual e de narrativas sequenciadas. Usa os cabeçalhos como bastidores, entre o design gráfico e a animação, ironizando o fazer da tipografia, da marca, do logotipo, do próprio jornal. As configurações técnicas abusam da metalinguagem e da intertextualidade para provocar inversões na dinâmica das páginas e do espaço privilegiado de visibilidade do mundo. O rigor e a agilidade de seu lápis traçam uma comédia das contradições e das transformações da sociedade, pessimista em relação ao futuro, mas antevendo extraordinárias soluções gráficas e narrativas, desenhando uma paródia da imprensa e de si mesmo. A tradição acadêmica ganhou ares de vanguarda nos gestos insanos do cavaleiro da triste figura, contaminados pela poética da desilusão de Agostini.

Notas

1. Ângelo Agostini nasceu em Vercelli, no Piemonte, ao norte da Itália e passou a infância e a adolescência em Paris. Por volta de 1859 chegou ao Brasil. Em São Paulo criou o Diabo Coxo (1864) e o Cabrião (1866). No Rio de Janeiro foi colaborador de O Arlequim (1897) e Vida Fluminense (1868). Fundou a Revista llustrada (18761891). Em 1889 foi para a Europa e só retornou em 1895. Neste mesmo ano, fundou D. Quixote (1895) e, mais tarde, colaborou com a revista infantojuvenil O Tico-Tico (1905). Para uma análise mais aprofundada de suas obras ver Maringoni (2011) e Balaban (2009).

2. A coleção do jornal Don Quixote foi consultada no acervo digital da Biblioteca Nacional. Ela está disponível em: http://bndigital.bn.br/hemeroteca-digital/. Acesso em: 01/ 02/2016.

3. Don Quixote foi publicado até 1903, com uma interrupção entre julho de 1897 e agosto de 1899 (Maringoni, 2011). 
4. Agostini travou batalhas visuais contra a escravidão, especialmente nas litografias da Revista llustrada, e apoiou as campanhas republicanas. A abolição dos escravos foi assinada em maio de 1888 e a República foi proclamada em novembro de 1889, sob o governo militar do Marechal Deodoro da Fonseca, seguido do governo do Marechal Floriano Peixoto. Este foi um período marcado pelo autoritarismo e pela centralização do poder, conhecido como a República da Espada.

5. Miguel de Cervantes Saavedra (1547-1616). A primeira parte de Dom Quixote foi publicada em 1605 e a segunda parte, em 1615.

Referências bibliográficas

Andrade, J. M. F. (2004). História da fotorreportagem no Brasil: a fotografia na imprensa do Rio de Janeiro de 1839 a 1900. Rio de Janeiro: Elsevier.

Balaban, M. (2009). Poeta do lápis. Sátira e política na trajetória de ângelo Agostini no Brasil Imperial. Campinas, SP: Editora da Unicamp.

Burke, P. (2004). Testemunha ocular: história e imagem. Bauru, SP: EDUSC.

Cagnin, A. L. (2005). "Foi o Diabo!", em Diabo Coxo: São Paulo, 1864-1865. Edição facsimilar. São Paulo, Edusp, pp. 9-19.

Ipanema, R. A estética de Don Quixote e a imagem difícil de Prudente de Morais. Em Anais do XXVII Simpósio Nacional de História (2013), disponível em http://www.snh2013.anpuh.

org/resources/anais/27/1370185093_ARQUIVO_2013-SNH-ANPUH-TEXTOREVISA DO-

AESTETICADEDONQUIXOTEEAIMAGEMDIFICILDEPRUDENTEDEMORAIS. pdf. Acesso em 22/03/2016.

Maringoni, G. (2011). Angelo Agostini. A imprensa ilustrada da Corte à Capital Federal, 1864-1910. São Paulo: Devir.

Velloso, M. P. (1996). Modernismo no Rio de Janeiro: turunas e quixotes. Rio de Janeiro: Editora Fundação Getúlio Vargas.

Fonte primária

Don Quixote (1895-1903).

Abstract: The purpose of this text is to reflect on the covers of the newspaper Don Quixote, founded in 1895, by the Italian immigrant Ângelo Agostini (1843-1910), emphasizing the metalinguistic resources created around the idea of the construction of the logo and the establishment of a sequenced narrative for the visual identity of the periodical. The context of disappointment with the republican oligarchic Brazilian regime and of distrust in the technological modernization dialogues with the confused adventures of the Cervantine characters in the lively headers of Agostini. The skilled academic stroke of the caricaturist experiments new directions for the language of graphic humor in lithography, revealing, although by a conservative bias, the transformations of the city and the press. 
Key words: Don Quixote - Agostini - comics - graphic humor.

Resumo: O objetivo deste texto é refletir sobre as capas do jornal Don Quixote, fundado em 1895, pelo imigrante italiano Ângelo Agostini (1843-1910), enfatizando os recursos metalinguísticos criados em torno da ideia de construção do logotipo e o estabelecimento de uma narrativa sequenciada para a identidade visual do periódico. O contexto de decepção com o início do regime republicano oligárquico brasileiro e de desconfiança com a modernização tecnológica dialoga com as confusas aventuras dos personagens cervantinos nos animados cabeçalhos de Agostini. O exímio traço acadêmico do caricaturista experimenta, na litografia, novos rumos para a linguagem do humor gráfico, deixando entrever, ainda que por um viés conservador, as transformações da cidade e da imprensa.

Palavras chave: Don Quixote - Agostini - quadrinhos - humor gráfico.

[Las traducciones de los abstracts al inglés y portugués fueron supervisadas por el autor de cada artículo]

Logotipo ou quadrinho? As animadas aventuras de Don Quixote nas capas de Ângelo Agostini fue publicado de la página 95 a página107 en Cuadernos del Centro de Estudios de Diseño y Comunicación №74 